\title{
URINE LEVELS OF PHTHALATE METABOLITES AND BISPHENOL A IN RELATION TO MAIN METABOLIC SYNDROME COMPONENTS: DYSLIPIDEMIA, HYPERTENSION AND TYPE 2 DIABETES A PILOT STUDY
}

\author{
Roman Piecha', Štěpán Svačina', Marek Malý2 ${ }^{1}$ Karel Vrbík², Zdenka Lacinová1, Martin Haluzík ${ }^{1}$, Jana \\ Pavloušková2, Adam Vavrouš², Dagmar Matějková3, Dana Müllerová3,4, Miloš Mráz', Martin Matoulek1 \\ 13rd Internal Clinic, 1st Medical Faculty in Prague, Charles University, Prague, Czech Republic \\ ${ }^{2}$ National Institute of Public Health, Prague, Czech Republic \\ ${ }^{3}$ Faculty Hospital in Pilsen, Pilsen, Czech Republic \\ ${ }^{4}$ Department of Public Health and Preventive Medicine, Faculty of Medicine in Pilsen, Charles University, Pilsen, Czech Republic
}

\section{SUMMARY}

Aim: Human exposure to organic pollutants (some of them also called endocrine disruptors) can be associated with adverse metabolic health outcomes including type 2 diabetes. The aim of this study was to compare the urine levels of bisphenol A and phthalate metabolites in subgroups of patients with metabolic syndrome composed of patients with and without three important components of metabolic syndrome (hypertension, dyslipidemia and diabetes).

Methods: We have investigated 24 hours urine samples of 168 patients with metabolic syndrome from the Metabolic Outpatient Department of General University Hospital in Prague. Using standard metabolic syndrome criteria, we classified patients as dyslipidemic $(n=87)$, hypertensive $(n=96)$, and type 2 diabetic $(n=58)$. Bisphenol $A$ and 15 metabolites of phthalates were evaluated in relation to creatinine excretion. Samples were analysed with enzymatic cleavage of glucuronide using ultra-high-performance liquid chromatography-electrospray ionization tandem mass spectrometry in one laboratory with external quality control.

Results: Four metabolites, mono-n-butyl phthalate, mono-(2-ethyl-5-hydroxyhexyl) phthalate, mono-(2-ethyl-5-oxohexyl) phthalate, and mono(2-ethyl-5-carboxypentyl) phthalate showed significantly higher levels in diabetic compared to non-diabetic patients $(p<0.001, p=0.002, p=0.002$, and $p=0.005$, respectively). The differences remained significant after adjustment to hypertension, dyslipidemia, age, and BMI. No difference was found between either the hypertensive and non-hypertensive or dyslipidemic and non-dyslipidemic patients. There was no significant relation of bisphenol A level to diabetes, hypertension, dyslipidemia, age, and BMI.

Conclusions: Urine levels of four phthalate metabolites were significantly higher in type 2 diabetics independently on specified predictors. Phthalate levels can be in relation to beta cell dysfunction in type 2 diabetic patients but this study was not able to show if the relation is causal.

Key words: organic pollutants, endocrine disruptors, phthalates, bisphenol A, metabolic syndrome, type 2 diabetes, obesity

Address for correspondence: R. Piecha, 3rd Department of Medicine, 1st Faculty of Medicine, U nemocnice 2, 12808 Prague, Czech Republic. E-mail: roman.piecha@vfn.cz

http://dx.doi.org/10.21101/cejph.a4704

\section{INTRODUCTION}

Human exposure to organic pollutants (some of them also called endocrine disruptors) may be associated with a risk of metabolic syndrome and type 2 diabetes (1-4). The molecular mechanisms involved are still largely unknown, but alteration of gene expression after binding to the aryl hydrocarbon receptor (AhR), peroxisome proliferator-activated receptor (PPAR), and estrogen receptors seems to play a role. The interaction between endocrine disruptors exposure and nuclear polymorphisms associated with obesity, type 2 diabetes, and cardiovascular disease is important (5). Longitudinal studies have found a long-term risk of type 2 diabetes and hypertension (6).

In the present study, we evaluated actual urinary levels of some organic pollutants (phthalates and bisphenol A) in relation to hypertension, dyslipidemia, and type 2 diabetes as well as to age and BMI, all related to metabolic syndrome. The study was conducted on a group of patients from the Metabolic Outpatient Department of University Hospital in Prague. The aim of this study was to compare the urine level of bisphenol A and phthalates in subgroups of patients with metabolic syndrome and patients with and without three important components of metabolic syndrome (hypertension, dyslipidemia and diabetes). 


\section{MATERIAL AND METHODS}

One hundred and sixty-eight patients with metabolic syndrome were included in the present study (57 males and 111 females). The mean age of our patients was 51.2 and 65 years for males and females, respectively. Basic characteristics of patients stratified to diabetics and non-diabetics are shown in Table 1.

Urinary phthalates and bisphenol A/creatinine ratio was analyzed in those who were coming consecutively to the Metabolic Outpatient Department, 3rd Department of Medicine, Prague. Patients were classified as dyslipidemic $(n=87)$, hypertensive $(\mathrm{n}=96)$, and with type 2 diabetes $(\mathrm{n}=58)$ according to metabolic syndrome criteria (7) and/or according to used pharmacotherapy. Phthalate metabolite levels were compared in patients with and without dyslipidemia, with and without hypertension, and with and without diabetes.

Fifteen different phthalate metabolites (Table 2) were analyzed in urine: mono-(3-carboxypropyl) phthalate (MCPP), monoethyl phthalate (MEP), monoisobuthyl phthalate (MiBP), mono-nbuthyl phthalate (MnBP), mono-(2-ethyl-5-hydroxyhexyl) phthalate (OH-MEHP), mono-(2-ethyl-5-oxohexyl) phthalate (OXOMEHP), mono-(2-ethyl-5-carboxypentyl) phthalate (cx-MEHP), monobenzyl phthalate (MBzP), mono-(4-methyl-7-oxo-octyl) phthalate (OXO-MMeOP), mono-(4-methyl-7-hydroxyoctyl) phthalate (OH-MMeOP), mono-(4-methyl-7-carboxyheptyl) phthalate (cx-MMeHP), mono-(2-propyl-6-carboxyhexyl) phthalate (cx-MPHxP), mono-(2-propyl-6-hydroxyheptyl) phthalate (OH-MPHP), mono-(2-propyl-6-oxo-heptyl) phthalate (OXOMPHP), and mono-(2-ethylhexyl) phthalate (MEHP).

Metabolites were analyzed with enzymatic cleavage of glucuronide using ultra-high-performance liquid chromatographyelectrospray ionization tandem mass spectrometry in one laboratory with external quality control. Detailed description of the analytic procedures was presented in the work of Vrbík et al. (8). For seven metabolites (MCPP, MBzP, cx-MMeHP, cx-MPHxP, OH-MPHP, OXO-MPHP, MEHP) more than $50 \%$ of values were less than the limit of quantification. These metabolites were not used for further comparisons. Creatinine-adjusted urinary concentrations (micrograms per gram creatinine) were analyzed. Great variability and asymmetrical distribution were seen in phthalate metabolites and bisphenol A levels. The location and variability of the data is characterized by median and interquartile range. Group comparisons were performed using non-parametric Mann-
Whitney test. Diabetes, hypertension, dyslipidemia, age, and BMI were evaluated as possible predictors of metabolite levels by multiple linear regression applied to logarithm of phthalate metabolite. All statistical tests were evaluated at a significance level of 0.05. Data were analyzed using statistical software Stata, release 9.2 (Stata Corp LP, College Station, TX).

\section{RESULTS}

\section{Diabetes Type 2 Patients}

Characteristics of creatinine-adjusted concentrations of selected metabolites (expressed as $\mu \mathrm{g} / \mathrm{g}$ ) are shown in Table 3 . Four metabolites (mono-n-butyl phthalate, mono-(2-ethyl-5hydroxyhexyl) phthalate, mono-(2-ethyl-5-oxohexyl) phthalate, and mono-(2-ethyl-5-carboxypentyl) phthalate) had significantly higher levels in type 2 diabetic in comparison to non-diabetic patients. There was no significant difference in the other four analyzed phthalate metabolites and in bisphenol A levels between patients with and without diabetes.

\section{Hypertensive and Dyslipidemic Patients}

There was no significant difference in any analyzed phthalate metabolite or in bisphenol A levels when comparing patients with and without hypertension and dyslipidemia.

\section{Age and BMI}

Multiple linear regression with five explanatory variables including age, BMI, diabetes type 2 , hypertension, and dyslipidemia showed that diabetes type 2 remains statistically significant predictor of four phthalates (MnBP, OH-MEHP, OXO-MEHP, and cx-MEHP) even after adjustment to four other variables included in the model. None of these variables was significant and so metabolite levels were substantially determined only by diabetes.

\section{DISCUSSION}

Phthalate exposure is related to many diseases including metabolic and cardiovascular diseases, cancer, allergy, developmental

Table 1. Basic characteristics of analyzed patients stratified by type 2 diabetes

\begin{tabular}{|l|c|c|c|}
\hline \multirow{2}{*}{ Phthalate metabolite } & \multicolumn{2}{|c|}{ Type 2 diabetes } & \multirow{2}{*}{ Total } \\
\cline { 2 - 4 } & Present & Absent & $57(33.9 \%)$ \\
\hline Male gender & $32(29.1 \%)$ & $25(43.1 \%)$ & $52.7(23.4)$ \\
\hline Age $($ years $)$ & $61.8(12.7)$ & $46.5(23.0)$ & $38.6(8.9)$ \\
\hline BMl $\left(\mathrm{kg} / \mathrm{m}^{2}\right)$ & $37.9(10.2)$ & $38.9(9.3)$ & $120.5(20.5)$ \\
\hline Waist circumference $(\mathrm{cm})$ & $120.0(23.5)$ & $121.0(21.0)$ & $4.66(1.14)$ \\
\hline Total cholesterol $(\mathrm{mmol} / \mathrm{l})$ & $4.74(1.18)$ & $4.65(1.19)$ & $1.29(0.43)$ \\
\hline HDL cholesterol $(\mathrm{mmol} / \mathrm{l})$ & $1.18(0.42)$ & $1.33(0.39)$ & $2.64(0.92)$ \\
\hline LDL cholesterol $(\mathrm{mmol} / \mathrm{l})$ & $2.56(1.01)$ & $2.66(1.01)$ & \\
\hline
\end{tabular}

Data are presented as median (interquartile range) except for gender where count and percentage is given.

$\mathrm{BMI}$ - body mass index, HDL - high-density lipoprotein, LDL - low-density lipoprotein 
Table 2. Phthalates and bisphenol A metabolites

\begin{tabular}{|c|c|}
\hline Phthatate (acronym) & Known metabolite (acronym) \\
\hline Dimethyl phthalate (DMP) & Monomethyl phthalate (MMP) \\
\hline Diethyl phthalate (DEP) & Monoethyl phthalate (MEP) \\
\hline Dibutyl phthalate (DBP) & Mono-n-butyl phthalate (MnBP) \\
\hline Diisobutyl phthalate (DIBP) & Monoisobutyl phthalate (MiBP) \\
\hline \multirow{2}{*}{ Benzylbutyl phthalate (BzBP) } & Monobenzyl phthalate (MBzP) \\
\hline & Mono-n-butyl phthalate (MnBP) \\
\hline Dicyclohexyl phthalate (DCHP) & Monocyclohexyl phthalate (MCHP) \\
\hline \multirow{5}{*}{ Di-(2-ethylhexyl) phthalate (DEHP) } & Mono-(2-ethylhexyl) phthalate (MEHP) \\
\hline & Mono-(2-ethyl-5-hydroxyhexyl) phthalate (OH-MEHP) \\
\hline & Mono-(2-ethyl-5-oxohexyl) phthalate (OXO-MEHP) \\
\hline & Mono-(2-carboxymethylhexyl) phthalate (cx-MMHP) \\
\hline & Mono-(2-ethyl-5-carboxypentyl) phthalate (cx-MEHP) \\
\hline \multirow{2}{*}{ Di-n-octyl phthalate (DNOP, DOP) } & Mono-n-octyl phthalate (MnOP) \\
\hline & Mono-(3-carboxypropyl) phthalate (MCPP) \\
\hline \multirow{7}{*}{ Diisononyl phthalate (DINP) } & Monoisononyl phthalate (MiNP) \\
\hline & Mono-(hydroxyisononyl) phthalate (OH-MINP) \\
\hline & Mono-(oxoisononyl) phthalate (OXO-MINP) \\
\hline & Mono-(carboxyisooctyl) phthalate (cx-MIOP) \\
\hline & Mono-(4-methyl-7-hydroxyoctyl) phthalate (OH-MMeOP) \\
\hline & Mono-(4-methyl-7-oxooctyl) phthalate (OXO-MMeOP) \\
\hline & Mono-(4-methyl-7-carboxyheptyl) phthalate (cx-MMeHP) \\
\hline \multirow{5}{*}{ Diisodecyl phthalate (DIDP) } & Monoisodecyl phthalate (MiDP) \\
\hline & Mono-(hydroxyisodecyl) phthalate (OH-MIDP) \\
\hline & Mono-(oxoisodecyl) phthalate (OXO-MIDP) \\
\hline & Mono-(carboxyisononyl) phthalate (cx-MINP) \\
\hline & Mono-(2-propyl-6-carboxyhexyl) phthalate (cx-MPHxP) \\
\hline \multirow{3}{*}{ Di-(2-propylheptyl) phthalate (DPHP) } & Mono-(2-propyl-6-hydroxyheptyl) phthalate (OH-MPHP) \\
\hline & Mono-(2-propyl-6-oxoheptyl) phthalate (OXO-MPHP) \\
\hline & Mono-(2-propyl-6-carboxyhexyl) phthalate (cx-MPHP) \\
\hline All phthalates & Phthalic acid (PA) \\
\hline 2,2-bis-(4-hydroxyphenyl) propane (BPA) & Bisphenol A \\
\hline
\end{tabular}

Phthalates and bisphenol A metabolites measured in our study are written in bold

disorders, hypogonadism, foetal malformations, depression, etc. (9). Phthalate exposure results mostly from plasticizers (substances added to plastics to increase their flexibility and longevity). They are mostly used for softening polyvinyl chloride (PVC). To the organism phthalates can come through food (mostly canned or in plastics packaging), through air pollution including home dust, and also from many skin care products $(10,11)$. In a previous study, urine phthalate excretion correlated well with the use of plastic packaging and skin care (12). However, use of phthalates in plasticizers has been significantly reduced and today mostly non-phthalate plasticizers are used (13).

Bisphenol $\mathrm{A}$ is an estrogenic compound and is coming to the body from plastics (14) and thermal print paper (15). Several clinical studies show that humans exposed to bisphenol A are more likely to incur reproductive disorders like reduction of spermatogenesis, decreased testosterone production or malformation of the genitals or induction of tumors like mammary carcinoma, immune function and allergy, obesity and diabetes $(4,16)$. Bisphenol A, a common and widely utilized chemical contaminant acting as endocrine disruptor, accumulates in adipose tissue and may affect adipocyte metabolic and inflammatory functions. At low chronic doses it is now considered an obesogen compound and it might contribute to the rise of metabolic syndrome, visceral adiposity and diabetes epidemics. Bisphenol $\mathrm{A}$ is present in the environment worldwide and it is responsible for chronic exposure during vulnerable periods, such as foetal and neonatal life. The source of contamination can occur via food, beverage, wastewater, air, dust, and soil. Bisphenol A, as lipophilic compound, 
Table 3. Measured levels of phthalate metabolites and bisphenol A in relation to $24 \mathrm{hr}$ creatinine excretion ( $\mu \mathrm{g} / \mathrm{g})$ stratified by type 2 diabetes

\begin{tabular}{|l|c|c|c|}
\hline \multirow{2}{*}{ Phthalate metabolite } & \multicolumn{2}{|c|}{ Type 2 diabetes } & \multirow{2}{*}{ p value } \\
\cline { 2 - 4 } & Present & $39.1(32.8)$ & $<0.001$ \\
\hline MnBP & $54.5(64.9)$ & $6.22(3.92)$ & 0.002 \\
\hline OH-MEHP & $9.43(8.46)$ & $4.64(3.80)$ & 0.002 \\
\hline OXO-MEHP & $6.79(6.90)$ & $38.0(26.6)$ & 0.005 \\
\hline CX-MEHP & $54.0(50.9)$ & $33.7(56.3)$ & 0.171 \\
\hline MiBP & $40.7(73.2)$ & $22.2(17.5)$ & 0.274 \\
\hline OXO-MMeOP & $20.4(17.0)$ & $2.68(3.74)$ & 0.931 \\
\hline OH-MMeOP & $2.61(4.58)$ & $8.05(11.68)$ & 0.957 \\
\hline Bisphenol A & $8.69(8.66)$ & $7.50(14.07)$ & 0.107 \\
\hline
\end{tabular}

Data are presented as median (interquartile range)

may accumulate into the adipose tissue already during foetal life and may affect adulthood health, through adverse effects on the growth and development of organs and tissues $(17,18)$.

Phthalates and bisphenol A are considered to be causative in the pathogenesis of diabetes type 2 and metabolic syndrome (1-5). Also, in a short exposure study where volunteers were exposed to phthalates (9), a non-significant trend to metabolic syndrome was also found. In the present study, we only confirmed the relation of some phthalate metabolites to type 2 diabetes and not to other components of metabolic syndrome in the Czech population. The aim of this study was not to compare the organic pollutant level in subjects with and without metabolic syndrome. We have compared the urine level of bisphenol A and phthalates in subgroups of patients with metabolic syndrome comparing patients with and without three important components of metabolic syndrome (hypertension, dyslipidemia and diabetes).

Specifically, we found that only 4 phthalate metabolites - mono-n-butyl phthalate, mono-(2-ethyl-5-hydroxyhexyl) phthalate, mono-(2-ethyl-5-oxohexyl) phthalate, and mono-(2ethyl-5-carboxypentyl) phthalate were related to the presence of type 2 diabetes. Our data is supported by the NHANES survey where a relation of similar subgroup of phthalate metabolites to type 2 diabetes was found. For example, geometric mean of MnBP was $20.1 \mathrm{ng} / \mathrm{mL}$ in diabetics and $17.6 \mathrm{ng} / \mathrm{mL}$ in nondiabetics (19). Median level of MnBP found in mothers from 17 European countries in the study DEMOCOPHES (20) was 22.0 $\mu \mathrm{g} / \mathrm{g}$ creatinine. If the cause of high urine phthalates excretion would be only exogenous (e.g. diet, skin care), it would elevate the level of majority or all phthalate metabolites. The elevation of only 4 metabolites without any relation to BMI, hypertension, dyslipidemia, or age can be explained by some diabetes specific changes in metabolism of these 4 phthalate metabolites, especially in the liver resulting in their high circulating levels and a possible effect on beta cell function. Further modification of the effect of these 4 metabolites could be also mediated by low plasma testosterone levels (21) and inflammation (22). Finally, endogenous production of some phthalates is linked to the presence of helicobacter pylori in stomach (23) and liver is the major source of phthalates metabolism, both organs to be affected by diabetes. Moreover, specific changes in liver metabolism were described in bisphenol $\mathrm{A}$ and can also be present in phthalates in some liver diseases, which are related to diabetes (24). Thus, additional studies should be performed in higher number of diabetic patients with possible division to specific type 2 diabetes subgroups and their testosterone and other hormonal levels as well as the more precise assessment of beta cell dysfunction. It should be noted, that our study is not a longitudinal study and it cannot be used for any risk calculation including specific components of metabolic syndrome.

\section{CONCLUSION}

In the present study, we found a statistically significant correlation between phthalate metabolites, urine excretion and type 2 diabetes in a group of patients with metabolic syndrome. Urine levels of 4 , but not of the other 11 phthalate metabolites were significantly higher in type 2 diabetes patients compared to those without diabetes. This influence was not related to BMI, dyslipidemia or hypertension. There was no significant difference in bisphenol A levels when comparing patients with and without diabetes, hypertension and dyslipidemia.

We concluded that high phthalate levels are in relation to type 2 diabetes. This study was not able to show if relation to beta cell dysfunction is causal. Further studies should be conducted to study in detail beta cell dysfunction in experimental and other models after the exposure of those metabolites.

\section{Acknowledgement}

This study was supported by a research grant of the Czech Ministry of Health IGA NT 14182-3.

\section{Conflict of Interests}

None declared

\section{REFERENCES}

1. Chevalier N, Fénichel P. Endocrine disruptors: new players in the pathophysiology of type 2 diabetes? Diabetes Metab. 2015 Apr;41(2):107-15.

2. Trasande L, Attina TM. Association of exposure to di-2-ethylhexylphthalate replacements with increased blood pressure in children and adolescents. Hypertension. 2015 Aug;66(2):301-8. 
3. Yaghjyan L, Sites S, Ruan Y, Chang SH. Associations of urinary phthalates with body mass index, waist circumference and serum lipids among females: National Health and Nutrition Examination Survey 1999-2004. Int J Obes (Lond). 2015 Jun;39(6):994-1000.

4. Rochester JR. Bisphenol A and human health: a review of the literature. Reprod Toxicol. 2013 Dec;42:132-55.

5. Gore AC, Chappell VA, Fenton SE, Flaws JA, Nadal A, Prins GS, et al. EDC-2: The Endocrine Society's Second Scientific Statement on Endocrine-Disrupting Chemicals. Endocr Rev. 2015 Dec;36(6):E1-E150.

6. Song Y, Chou EL, Baecker A, You NC, Song Y, Sun Q, et al. Endocrinedisrupting chemicals, risk of type 2 diabetes, and diabetes-related metabolic traits: A systematic review and meta-analysis. J Diabetes. 2016 Jul;8(4):516-32.

7. Lam DW, LeRoith D. Metabolic syndrome. In: De Groot LJ, Chrousos G, Dungan K, Feingold KR, Grossman A, Hershman JM, et al, editors. Endotext [Internet]. South Dartmouth (MA): MDText.com, Inc.; 2000 [cited 2016 May 4]. Available from: https://www.ncbi.nlm.nih.gov/books/ NBK278936/.

8. Vrbík K, Vavrouš A, Pavloušková J, Malý M, Svačina Š, Piecha R, et al. Determination of phthalates and bisphenol A and their metabolites in different types of materials. Klin Biochem Metab. 2016;24(3):153-9.

9. Medic Stojanoska M, Milankov A, Vukovic B, Vukcevic D, Sudji J, Bajkin I, et al. Do diethyl phthalate (DEP) and di-2-ethylhexyl phthalate (DEHP) influence the metabolic syndrome parameters? Pilot study. Environ Monit Assess. 2015 Aug;187(8):526. doi: 10.1007/s10661-015-4754-5.

10. Klingmüller D, Alléra A. Endocrine disruptors: hormone-active chemicals from the environment: a risk to humans? Dtsch Med Wochenschr. 2011 May;136(18):967-72. (In German.)

11. Koch HM, Lorber M, Christensen KL, Pälmke C, Koslitz S, Brüning T. Identifying sources of phthalate exposure with human biomonitoring: results of a $48 \mathrm{~h}$ fasting study with urine collection and personal activity patterns. Int J Hyg Environ Health. 2013 Nov;216(6):672-81.

12. Cao Y, Liu J, Liu Y, Wang J, Hao X. An integrated exposure assessment of phthalates for the general population in China based on both exposure scenario and biomonitoring estimation approaches. Regul Toxicol Pharmacol. 2016 Feb;74:34-41.

13. Müllerová D, Bouchalová V, Matějková D, Kovářová K, Svačina Š, Vrbík K, et al. Phthalates exposure indicators determined by urinary phthalate metabolites in healthy non-obese Czech adults: FANTOM study. Food Addit Contam Part A Chem Anal Control Expo Risk Assess. 2016 Dec;33(12):1817-25.

14. Alonso-Magdalena P, Ropero AB, Soriano S, García-Arévalo M, Ripoll $\mathrm{C}$, Fuentes E, et al. Bisphenol-A acts as a potent estrogen via nonclassical estrogen triggered pathways. Mol Cell Endocrinol. 2012 May 22;355(2):201-7.
15. Thayer KA, Taylor KW, Garantziotis S, Schurman SH, Kissling GE, Hunt D, et al. Bisphenol A, Bisphenol S, and 4-Hydroxyphenyl 4-Isoprooxyphenyl sulfone (BPSIP) in Urine and Blood of Cashiers. Environ Health Perspect. 2016 Apr;124(4):437-44.

16. Mikołajewska K, Stragierowicz J, Gromadzińska J. Bisphenol A - Application, sources of exposure and potential risks in infants, children and pregnant women. Int J Occup Med Environ Health. 2015;28(2):209-41.

17. Robinson L, Miller R. The Impact of Bisphenol A and Phthalates on Allergy, Asthma, and Immune Function: a Review of Latest Findings. Curr Environ Health Rep. 2015 Dec;2(4):379-87.

18. Valentino R, D'Esposito V, Ariemma F, Cimmino I, Beguinot F, Formisano P. Bisphenol A environmental exposure and the detrimental effects on human metabolic health: is it necessary to revise the risk assessment in vulnerable population? J Endocrinol Invest. 2016 Mar;39(3):259-63.

19. James-Todd T, Stahlhut R, Meeker JD, Powell SG, Hauser R, Huang T, et al. Urinary phthalate metabolite concentrations and diabetes among women in the National Health and Nutrition Examination Survey (NHANES) 2001-2008. Environ Health Perspect. 2012 Sep;120(9):130713.

20. Den Hond E, Govarts E, Willems H, Smolders R, Casteleyn L, KolossaGehring M, et al. First steps toward harmonized human biomonitoring in Europe: demonstration project to perform human biomonitoring on a European scale. Environ Health Perspect. 2015 Mar;123(3):255-63.

21. Koch HM, Calafat AM. Human body burdens of chemicals used in plastic manufacture. Philos Trans R Soc Lond B Biol Sci. 2009 Jul 27;364(1526):2063-78.

22. Hansen JF, Bendtzen K, Boas M, Frederiksen H, Nielsen CH, Rasmussen $\AA \mathrm{K}$, et al. Influence of phthalates on cytokine production in monocytes and macrophages: a systematic review of experimental trials. PLoS One. 2015 Mar 26;10(3):e0120083. doi: 10.1371/journal.pone.0120083.

23. Hilton GM, Hoppin JA. Is Helicobacter Pylori an endogenous source of diethyl phthalate in humans? Environ Res. 2014 Oct;134:402-4.

24. Yalcin EB, Kulkarni SR, Slitt AL, King R. Bisphenol A sulfonation is impaired in metabolic and liver disease. Toxicol Appl Pharmacol. 2016 Feb 1;292:75-84.

Received January 18, 2016

Accepted in revised form May 5, 2016 